\title{
Entrevista
}

\section{La masonería española en Marruecos: un proyecto colonial (1881-1936)}

\author{
Valeria Aguiar Bobet \\ Universitat Jaume I, Castellón, España \\ vaguiar@uji.es
}

Tesis de doctorado en historia defendida en la Universidad Jaume I en España, el 8 de enero de 2020. https://doi.org/10.15517/rehmlac.v12i1-2.40724

\section{¿Cuáles fueron los motivos que le llevaron a enfocar su investi- gación en la masonería?}

Cuando mi profesor, quien sería mi futuro director de tesis, Manuel de Paz me planteó la posibilidad de trabajar sobre la masonería española en Marruecos, admito que tenía escasos conocimientos sobre el tema. La masonería para mí estaba ensombrecida a causa de su versión mitificada y distorsionada, la versión o las versiones producto de décadas intensas y eficaces de discurso complotista, sectarista y cual poder en la sombra. Es decir, mi percepción de la masonería cubría todos los tópicos existentes sobre los Hijos de la Viuda. A mi favor añadiré que tampoco era un tema que se tratase en la carrera de Historia que, en el caso de mi plan de estudios, fueron cinco años y unas 12 asignaturas entre historia moderna, contemporánea y actual, contando las generales, las de España y las de Canarias. La masonería, entonces, después de otras propuestas menos sugerentes de mi profesor, despertó en mí el recelo del misterio de la historia, tal y como les sucede a otras personas inexpertas.

Sin embargo, la seducción final del tema no fue este primer principio de la seducción académica, sino otra variable: Marruecos. Marruecos, tan cerca y tan lejos de las Islas Canarias, mi hogar, fue presentado por Manuel de Paz como un crisol de culturas -término que más adelante guiaría mi propuesta de tesis-, como un crisol multicultural que se concentraría en el seno de la masonería española. Cristianos, musulmanes y judíos se habían iniciado en las logias instauradas durante la época colonial, sobre todo durante la Segunda República, motivando una situación de convivencia, tolerancia y fraternidad. La idea, vaga pero potente a priori, despertó mi verdadero interés por la historia: era una oportunidad, una muestra, si se me permite, no solo de estudiar la masonería, la posible interculturalidad experimentada en las logias masónicas y la relación de las tres culturas por antonomasia en un marco tan ambivalente y complejo como el periodo republicano, sino porque se trataba de un tema con una clara conexión con nuestro presente. La globalización, las migraciones, los problemas interétnicos e interreligiosos son una variable constante en todos los países del mundo. Analizar este mismo caso de forma pretérita, con el añadido de las tesis evolucionistas y todos los imaginarios culturales más y menos peyorativos, era el cóctel perfecto para hacer "historia actual" - y qué historia no lo es-, es decir, para tratar uno de los principales problemas a los que nos enfrentamos en la actualidad. Problemas que, en este caso, se mezclan, sobre todo, 
con el terrorismo islámico, los miles de refugiados y migrantes que cada día se enfrentan no ya a la emigración en sí, sino a la adaptación y a la aceptación de otras alteridades.

En fin, lo que quiero decir con ello es que la masonería española en Marruecos me permitía satisfacer mis inquietudes historiográficas más generales: desmitificar la propia orden (incluyendo mis propias ideas); contribuir con la literatura histórica española sobre Marruecos - pues, al fin y al cabo es una línea menos conocida y trabajada que otras zonas que también fueron colonias hispanas, especialmente las americanas-, y utilizar esta pequeña muestra de nuestro pasado, para tratar problemáticas actuales centradas en la pluriculturalidad, las alteridades y la convivencia derivada, en el caso de mi tesis, del colonialismo y la colonización.

Con todo, al final, tales objetivos hicieron que terminara ampliando el objeto de estudio: si bien en un principio la tesis debía ceñirse exclusivamente a la II República y a la Gran Logia Regional de Marruecos, tres años más tarde se transmutó en toda la historia de la orden en el territorio, al menos de todas las logias de obediencia española en el Imperio cherifiano, incluyendo Tánger - que tendría un estatuto internacional propio- y la zona francesa en el momento del reparto colonial. Mi investigación, de este modo, pasó de 1931 a $1881-\mathrm{y}$ un poco antes también- hasta 1936/38, momento en que la masonería hispano-marroquí desaparece y es perseguida por el nuevo Estado nacional.

\section{¿Cuáles fueron las fuentes utilizadas?}

La verdad es que he usado una cantidad de fuentes considerable, y no solo exclusivamente masónicas, también hemerográficas, cartas y documentos personales y diversas publicaciones más o menos literarias de la época. No obstante, el grueso de la documentación utilizada provino del Centro Documental de la Memoria Histórica de Salamanca que, como es sabido, es el organismo que concentra la mayor parte de los expedientes de las logias españolas y casi todas las fuentes relativas a la guerra civil y la represión. De hecho, el Protectorado español, junto a Canarias, fueron las primeras zonas donde se incautaron los archivos personales y masónicos de los individuos implicados en la orden, justo al comienzo del alzamiento el 18 de julio de 1936, por lo que, salvo algunos que se habrían extraviado o destruido (por los propios masones o por sus familias), el Centro de la Memoria cuenta con más de mil expedientes personales y de logias. Además, claro está, de otros documentos más generales, como son los de las obediencias hispanas, las revistas y boletines, los expedientes del Tribunal de la Represión y fotografías.

Prácticamente, podría haber escrito la tesis a partir de estas referencias, no solo por su cantidad sino por su cualidad: los expedientes personales, sobre todo, albergan una gran suma de datos privados y de ensayos intelectuales que permiten hacer estudios muy interesantes sobre discursos, redes sociales e ideológicas, historias conectadas, etcétera. Pero también es cierto que para algunas zonas y etapas concretas no se han conservado de forma homogénea las fuentes históricas. La masonería republicana (1931-1936) es la que contiene más referencias, mientras que los primeros pasos de la orden (1881-1906) presentan menos legajos. Lo mismo sucede con la zona tangerina y francesa, ya que los emisarios del nuevo Estado español no tuvieron tantas 
facilidades para incautar los archivos que en el Protectorado español. En Tánger tuvieron que esperar hasta 1940 y en la zona francesa hasta el régimen de Vichy, y aun así, parece que la mayor parte pudo ser destruida, especialmente los expedientes personales de los masones, de los que apenas se han conservado algunos documentos de carácter administrativo e institucional, aquellos que debían ser remitidos a las obediencias regionales y nacionales.

En cualquier caso, para terminar de completar las "ausencias" de fuentes históricas de tales periodos y zonas, tuve la oportunidad de consultar otros "archivos masónicos”, como el Gran Oriente de Francia y el fondo específico de la Biblioteca Nacional Francesa, ambos en la "Île de France", en París. Y aunque el volumen previsto fue menor del que esperaba, pude subsanar algunos vacíos. También para ello tuve que acceder a otros organismos españoles como el Archivo General de la Administración, la Biblioteca Nacional Española, el Archivo Intermedio Militar de Ceuta; otros franceses, los diplomáticos de La Courneve y Nantes, la Biblioteca Nacional de Estrasburgo, y, por último, también centros marroquíes, como la Biblioteca General de Tetuán y algunos archivos privados.

En general, esta documentación adicional aportó, entre otras cosas, la otra cara de la moneda, es decir, artículos de prensa local, española y francesa (para la opinión pública y aquello que se publicaba en los diferentes periodos), las informaciones conservadas de las instituciones del Protectorado español y francés, sumamente interesantes y que podrían dar para una tesis en sí misma. Esto, sobre todo, en relación con las galas, que contienen informes precisos y detallados de cada año y región sobre individuos e instancias de la zona española; entre otro tipo de datos económicos, sociales y políticos relacionados con la masonería hispano-marroquí o con sus partícipes (los nacionalistas marroquíes, miembros de la comunidad judía, funcionarios militares y civiles al servicio del Protectorado, simpatizantes del sionismo, etcétera).

\section{¿Cuáles fueron las principales dificultades con las que se encontró? ¿Cómo las ha superado?}

Como más arriba mencioné, la primera dificultad con la que me encontré fue con la falta de documentación para algunas zonas y etapas, y viceversa, la gran cantidad de fuentes existentes para el periodo republicano, sobre todo de expedientes personales con numerosas cartas privadas y pequeños pseudoensayos de diferente temática. En este caso, ordenar y clasificar las fuentes mediante ficheros de individuos y de logias, además de hacer una pequeña base de datos de estas informaciones, fue necesario para poder construir el paisaje histórico propuesto y, sobre todo, para poder contrastar la información obtenida de los diversos fondos documentales. Pero, además, este esfuerzo valió la pena por la riqueza discursiva de la mues-

tra, y porque, gracias a ello, también me percaté de que era necesario abordar la masonería desde sus inicios. Me refiero a que, estableciendo las diferencias y las relaciones socioculturales y etnoreligiosas de los masones de las logias hispano-marroquíes, observé que existía cierta continuidad respecto a las etapas precedentes, es decir, que el proyecto masónico español para el Imperio marroquí hundía sus bases más allá de los años treinta. Y, por supuesto, esta diacronía me interesaba, teniendo en cuenta los objetivos con los que inicié la tesis, para descubrir y analizar tales bases. 
De esta forma, también me encontré, sin apenas ser consciente en un principio, con la segunda gran dificultad: organizar y estructurar lo que quería contar, los cientos de ítems que interferían en el análisis para hacer una historia conectada, para que fueran las fuentes las que hablasen y los propios sujetos de esta representación del pasado. Más de 20 índices iniciales del estudio, que se fueron modificando sobre la marcha, fueron la prueba de ello. Al final, me decanté, en primer lugar, por observar aquellos posibles cambios que pudiesen indicar que empezaba un nuevo proceso, aunque las bases del proyecto colonial masónico fuesen las mismas. Las variables fueron políticas, en relación con España y con Marruecos, el propio desarrollo de la masonería en España, esto es, la trayectoria de las obediencias con representación en Marruecos, y, por último, la evolución y expansión de la masonería hispano-marroquí. De ahí establecimos y delimitamos cuatro etapas que consideramos bastante acertadas, y en las que, además de abordar la historia interna de los implicados y de los talleres, analizamos las relaciones entre las alteridades de los diferentes miembros, sus percepciones ante el contexto vivido, las autopercepciones en función de los roles coloniales, entre otras variables (la condición etnoreligiosa y etnocultural, la socio-económica, el orientalismo/africanismo, el anticlericalismo, el colonialismo, etcétera).

En este sentido, también fue considerablemente complicado tener en cuenta tales variables propuestas a la hora de analizar las etapas y, dentro de ellas, la trayectoria de las diferentes zonas e individuos. Por eso, considero que una parte importante del ejercicio de la historia, de la representación del pasado, es hacer un buen uso de las fuentes. Y con ello quiero decir que debemos exprimirlas al máximo, dejar que hablen, pero también cuestionarlas e intentar comprenderlas y explicarlas. Uno de los modos que utilicé para ello, además de presentar una valoración general de la documentación utilizada para cada etapa junto a una aproximación al contexto histórico, fue incluirlas - transcribirlas - en la tesis. Es decir, introducir fragmentos o diseccionar sus partes. Y así, ofrecer al lector el proceso y el resultado del análisis seguido y de las conclusiones obtenidas. Algo que, entre otras cosas, también puede permitir a otros investigadores contrastar mis valoraciones u obtener diferentes visiones. Creo que como historiadores debemos ceñirnos a ello sin quitarles importancia a la teoría y la metodología, pero, sobre todo, para no olvidarnos de que son las fuentes, las palabras de los individuos que nos las han legado, las que nos dan las claves para construir la historia. Las fuentes deben ser siempre eje, el principio y el fin.

En último lugar, debo añadir la redacción de la investigación a este listado de problemas. Creo que escribir, al final, es la parte más compleja. Está directamente relacionada con la dificultad anterior, pero se diferencia en una cosa: el acto de escribir es crear, y crear es interpretar las fuentes, la realidad de los hechos. Debes ser claro, debes justificarte y ser consciente de lo que supone la creación. Es decir, debe haber una parte ética y tangible, de que el historiador, la historiadora en mi caso, conoce sus propias limitaciones, y las propias limitaciones de las fuentes, de la metodología y de la teoría que emplea. Y uno de los elementos clave que permite hacer este ejercicio es abrir más posibilidades analíticas, dejando clara la multicausalidad de los procesos que abarca y las otras muchas variables con las que podría analizarse. Como un gran colega investigador me dijo una vez: "cuando evalúo las tesis doctorales, valoro más lo que se deja ‘abierto' y las preguntas que surgen como novedad al acto de escribir, que lo que se ‘cierra”. 


\section{¿Cuáles fueron las principales problemáticas históricas que su tra- bajo ha resuelto?}

Esta es una pregunta trampa porque desde mi punto de vista, las problemáticas históricas nunca terminan de resolverse. Es una paradoja necesaria en la ciencia. Otro investigador, con las mismas fuentes que yo he trabajado, hubiese abordado el tema de otra forma y quizás, hubiese llegado a otras conclusiones. En cualquier caso, más que resolver, he podido solventar algunos vacíos existentes, por ejemplo, respecto a la historia de la masonería colonial española en Marruecos, apenas conocida. Y, junto a ello, contribuir con diversos debates en torno a las diferentes funciones de la masonería y en torno a las dimensiones discursivas e identitarias de los sujetos partícipes de la institución, en cuanto individuos y en cuanto a grupos más o menos definidos y autopercibidos.

Lo más obvio en este caso fue componer el paisaje histórico de la presencia de las diferentes obediencias hispanas en el territorio marroquí, esto es, su institución, expansión, evolución, su desestructuración y final, marcado por la guerra civil y la represión, a la que nos aproximamos sucintamente. En este sentido, hemos podido mostrar la cartografía y el estudio geoespacial y diacrónico de una de las muchas masonerías coloniales y colonialistas que han existido a lo largo de la historia; la vida interna y externa de las logias, las relaciones sociales y las diferentes redes de sus participantes, sus preocupaciones socioculturales y políticas, además de su condición colonial a través del proyecto que construyeron para Marruecos. Un proyecto que fue ideado tanto por españoles como por los marroquíes - esencialmente judíos sefardíes - desde los primeros pasos de la orden. Como añadido y con relación al carácter pluricultural de esta masonería, hemos podido analizar y valorar el papel de orden respecto al judaísmo, el islamismo y al mito andalusí que, hasta ahora, poco o muy poco, han sido abordados por la historiografía.

El último ítem, centrado en el mito de las tres culturas, ha sido, por ende, una de las máximas de la investigación, puesto que, junto con los ideales elementales de la masonería, se configuró y apropió por los diferentes grupos etnoculturales y etnoreligiosos como base ideológica de las logias y grandes logias constituidas, como un punto de unión entre las partes, entre las alteridades que convivían en ellas y en Marruecos en general. Y esto, inevitablemente, nos llevó al estudio de la función de la masonería como abstracción, por un lado, como institución, por otro, y, por último, a la función de las logias como espacios de pacto y espacios neutrales en el mundo colonial. Espacios en los que se adaptaron y readaptaron las diferentes identidades, experimentando diferentes procesos de resignificación, diglosias, hibridismos y, en definitiva, una pluralidad y una ambivalencia discursiva que, entre otras cosas, produjo su propio legado documental. Un legado que refleja esta complejidad identitaria y de pacto producto de la convivencia colonial entre alteridades que encontraron en la masonería y en el mito andalusí un nexo común sobre el que solventar las diferencias, y sobre el que actuar en Marruecos.

De todos modos, esto no significó que el peso del colonialismo y del africanismo español, de las tesis racialistas y evolucionistas, o de la propia "patria" hispana, fuesen fronteras ineludibles al proceso. Es más, las extralimitaciones contextuales y conceptuales del proyecto 
masónico siempre fueron a la par de la propia realidad política de cada uno de los gobiernos españoles, de las instituciones coloniales, y de las propias contradicciones ideológico-políticas de los masones hispano-marroquíes. Por ello consideramos que esta tesis es un ejemplo de cómo desde el estudio de la masonería hispano-marroquí como muestra de la historia, se pueden obtener resultados muy interesantes para comprender las relaciones entre España y Marruecos - y también Francia-, y para comprender mejor los procesos relacionados con la convivencia y la interacción entre alteridades, alteridades que se encuentran por la colonización, por ideas, redes o instrumentalizaciones compartidas, por esperanzas y utopías ante los diferentes contextos que viven y ante situaciones inevitables.

\section{Por favor, ¿podría resumir la esencia de su tesis en dos líneas?}

En dos no sé, pero en cuatro o cinco creo que podría. La masonería española en Marruecos es una muestra histórica de la convivencia etnocultural y etnoreligiosa inevitable del colonialismo. Una muestra que presenta elementos imprescindibles de análisis para entender por qué, ante determinadas situaciones y contextos, volvemos una y otra vez al mito de las tres culturas y a los ideales más elementales de la masonería, especialmente en un mundo afectado por la globalización y la pluriculturalidad.

\section{¿Cuáles fueron las lecciones, a todos los niveles, personal y profe- sional, que usted ha deducido de su experiencia investigativa?}

Profesionalmente, abarcar un trabajo tan largo y extenso - que me ocupó finalmente 1200 páginas-, ha sido una lección sobre resistencia y paciencia en general, pero, sobre todo, una lección para comprender las dificultades y el esfuerzo que supone escribir una monografía, que es muy diferente a abordar un artículo. En este sentido, es un ejercicio esencial para cualquier investigador. Después de escribir la tesis, parece que todo es posible.

En todo caso, una investigación de estas dimensiones te permite organizarte y estructurarte mejor, tanto en la parte investigativa como en la de redacción. Observas el problema y la muestra como un todo con diferentes partes, lo que te ofrece más perspectiva para comprobar y comprender los cambios y las continuidades de tu sujeto de estudio. Y esto, inevitablemente, te permite abordar mejor otras investigaciones posteriores. Ya sabes qué dificultades puedes encontrar y cómo resolverlas, fundamentalmente las más generales, aquellas que se pueden encontrar casi en cualquier objeto de investigación histórica.

Otro de los aprendizajes importantes ha sido el no "cerrar" el tema desde el principio. Comienzas con unos objetivos, con una idea, pero no debes circunscribirte a ello, debes dejar que las fuentes te guíen para poder obtener el máximo beneficio de ellas. Y, aunque no puedas abordar todas las posibilidades en un mismo estudio, sí que abres la puerta a otras investigaciones y a otros problemas. Creo que es importante tener en cuenta esta volatilidad o flexibilidad de las fuentes para que la teoría no acabe subyugando al objeto y a los problemas planteados. 
Por último, a nivel personal, el aprendizaje fue igual de relevante. El sacrificio que supone, las continuas frustraciones, la falta de concentración con las que muchas veces se debe lidiar, o la falta de motivación que también es una sombra constante y potente, me permitieron conocer mis propias limitaciones. Con ello me refiero a saber cuándo era mejor descansar, en qué horario me concentraba y escribía mejor, y así poder gestionar la frustración añadida que siempre suponen las tesis doctorales. De todos modos, una vez te das cuenta de que sí, que poco a poco y cada día "las cosas van saliendo", te sorprendes al pensar que ya ningún libro ni ningún artículo serán tan complicados como este primer gran esfuerzo académico. Paciencia, una mayor capacidad de análisis, de ejercicio retrospectivo e introspectivo, son los regalos que este proceso me ha traído. Y, sin duda alguna, ha valido la pena.

\section{Ahora, ¿cuáles son sus proyectos profesionales?}

Pues la publicación de la tesis, que creemos que será mejor dividirla en cuatro tomos. Una tarea complicada porque está escrita de forma redonda e interrelacionada. Pero, aparte de ello, estoy preparando otras publicaciones relacionadas con aquellas partes que no pude completar en la investigación doctoral o que tuve que restringir - porque si no, no hubiese terminado nunca-. Me gustaría especialmente continuar con el periodo de la guerra civil y la represión, pero no en sí mismas, aunque también, sino a través de los discursos de los masones perseguidos y represaliados, y de los mitos en torno a la masonería producto y resultado de la nueva situación en España y en Marruecos.

También me gustaría continuar con el estudio del mito andalusí, sobre todo ahora que más publicaciones lo tratan y que tan actual es por su relación con la interculturalidad que demandan algunas instituciones desde la política y desde la academia, como en mi caso; o por la apropiación que hacen diferentes grupos del propio mito, como puede ser el fundamentalismo islámico, ISIS, la identidad nacional de los marroquíes, o la propia de España. De hecho, en relación con este tema, sobre todo por las interacciones entre alteridades, estoy coordinando una obra colectiva, pero con el foco en el Norte de África y a través de diferentes grupos y fuentes (literarias, prensa, etcétera.). También habrá algún capítulo sobre la masonería, pero el tomo se centrará en diferentes colectivos. Investigadores jóvenes y expertos, tanto historiadores como filólogos, participarán en ella.

Pero también quisiera continuar con la historia conectada y la historia global, comparando las situaciones masónicas coloniales entre Marruecos y otros países arabo-islámicos, fundamentalmente porque en otros territorios no existía el componente añadido y diferencial de la masonería española, que son aquellos judíos y musulmanes expulsados de Castilla y que continuaron su andadura en Marruecos y otros países sin olvidar sus orígenes. Todos aquellos que, dentro de la orden, retomaron y reconstruyeron el mito andalusí de las tres culturas. Este aspecto diferencial a priori de otras masonerías coloniales podría servir para tratar diferentes analogías y situaciones masónicas más o menos similares. Además, existen diversos estudios sobre la masonería italiana en Turquía, la francesa en Argelia y otros países africanos, así como las experiencias de Palestina, Egipto, Siria, etcétera. También sería oportuno dedicarle una investigación exclusiva a la relación entre la masonería española y francesa en Marruecos, 
apenas tratada por la historiografía de ambos países. En la tesis, incluyo diversas referencias y conexiones por las relaciones que presentaron, pero creo que sería más provechoso abordar un artículo específico y con mayor profundidad.

Asimismo, en relación con la masonería, pero desde otros ámbitos, estoy realizando algunos trabajos relativos a las redes entre América-Canarias y África, pues existió un flujo importante de individuos entre las tres zonas. Los estudios conexos con las Islas siempre están y estarán ahí para mí gracias a los contactos continuos con la Universidad de La Laguna, con mi director y otros muchos investigadores con los que he compartido y comparto proyectos.

\section{¿Quisiera destacar algún aspecto que no se ha contemplado y que usted consideraría digno de reseñar?}

Sí. Me gustaría utilizar este espacio para vindicar los estudios históricos de la masonería como una muestra más de todas las posibilidades de la historia. Una muestra que presenta multitud de posibilidades analíticas por la naturaleza de sus fuentes, independientemente del interés o no de los investigadores por la institución masónica en sí. Los que trabajamos este tema entenderán a qué me refiero. En mi caso, este problema ha sido doble: ni la historia de la masonería presenta el reconocimiento que merece ni la historia de Marruecos, por ahora, tampoco. De sobra son conocidos los motivos, así que, me gustaría invitar a otros investigadores a que nos lean, a que observen la potencialidad de este objeto de estudio, obviando su mitificación y distorsión positiva o negativa. La historia de la masonería tiene mucho que ofrecer, y en España más aún, pues, aunque sea por un motivo triste y desagradable - la represión e incautación realizada durante el franquismo-, contiene miles y miles de expedientes personales, correspondencia masónica y no masónica, discursos... que son un regalo para el historiador contemporáneo y actual.

Por último, me gustaría agradecer al equipo de la revista $R E H M L A C+$ el apoyo académico que me ha brindado durante estos años, su interés en esta entrevista y en mi trabajo y, especialmente, su labor como mediadora y potenciadora de los estudios historiográficos sobre la masonería en todo el globo. Y, por supuesto, a mis directores de tesis, Manuel de Paz y José Antonio Piqueras, y a la Universidad Jaime I, por estos años de esfuerzo conjunto.

Esta entrevista se efectuó de forma telemática entre el 15 y 16 de febrero de 2020. Autores de la entrevista: Ricardo Martínez Esquivel e Yván Pozuelo Andrés, director y editor de REHMLAC+. 